\title{
Understanding the Influence of Consumer Embeddedness in Online Communities: An Abstract
}

\author{
Cheng-Chieh Hsiao
}

\begin{abstract}
In the era of digitalization, each consumer often has a virtual identity and tends to be embedded in a particular online community. However, the types and effects of a consumer's embeddedness in an online community have not been fully examined. Following Zukin and DiMaggio (1990), this study attempts to investigate how four types of consumer embeddedness (i.e., cognitive, cultural, structural, and political embeddedness) affect consumer loyalty in online communities of a famous massive multiplayer online game. The mediating role of consumer-community identification is also examined in the proposed model. The results show that these types of online community embeddedness are positively related to consumercommunity identification, which in turn affects consumer loyalty positively. Finally, this study concludes with several theoretical and practical implications for digital marketing.
\end{abstract}

C.-C. Hsiao (ه)

Shih Hsin University, Taipei, Taiwan

e-mail: jerrycchsiao@gmail.com 